ORIGINAL ARTICLE

doi:10.1111/evo.12314

\title{
QUEEN SIGNALING IN SOCIAL WASPS
}

\author{
Jelle S. van Zweden, ${ }^{1,2,3}$ Wim Bonckaert, ${ }^{2}$ Tom Wenseleers, ${ }^{2}$ and Patrizia d'Ettorre ${ }^{1,4}$ \\ ${ }^{1}$ Centre for Social Evolution, University of Copenhagen, Universitetsparken 15, 2100 Copenhagen, Denmark \\ ${ }^{2}$ Laboratory of Socioecology and Social Evolution, KU Leuven, Naamsestraat 59, box 2466 3000, Leuven, Belgium \\ ${ }^{3}$ E-mail: jelle.vanzweden@bio.kuleuven.be \\ ${ }^{4}$ Laboratoire d'Ethologie Expérimentale et Comparée, Université Paris 13, 99 avenue Jean-Baptiste Clément, 93430 \\ Villetaneuse, France
}

Received May 14, 2013

Accepted October 10, 2013

Social Hymenoptera are characterized by a reproductive division of labor, whereby queens perform most of the reproduction and workers help to raise her offspring. A long-lasting debate is whether queens maintain this reproductive dominance by manipulating their daughter workers into remaining sterile (queen control), or if instead queens honestly signal their fertility and workers reproduce according to their own evolutionary incentives (queen signaling). Here, we test these competing hypotheses using data from Vespine wasps. We show that in natural colonies of the Saxon wasp, Dolichovespula saxonica, queens emit reliable chemical cues of their true fertility and that these putative queen signals decrease as the colony develops and worker reproduction increases. Moreover, these putative pheromones of $D$. saxonica show significant conservation with those of Vespula vulgaris and other Vespinae, thereby arguing against fast evolution of signals as a result of a queen-worker arms race ensuing from queen control. Lastly, levels of worker reproduction in these species correspond well with their average colony kin structures, as predicted by the queen signaling hypothesis but not the queen control hypothesis. Altogether, this correlative yet comprehensive analysis provides compelling evidence that honest signaling explains levels of reproductive division of labor in social wasps.

KEY WORDS: Animal communication, cuticular hydrocarbons, honest signal, pheromone, reproductive division of labor, Vespidae.

An essential step in the evolution of sociality is the maintenance of group stability through the suppression of intragroup conflicts (Bourke 2011). Hymenopteran societies, such as ants, bees, and wasps, have long been a model in the study of such social conflicts and the mechanisms that can help to resolve them (Ratnieks et al. 2006). They are characterized by a reproductive division of labor, whereby the queen performs most of the reproduction and the workers generally remain sterile to help the queen reproduce (Wilson 1971), but because workers of many species have retained their ovaries, a reproductive conflict between queen and workers arises. The queen may signal her reproductive dominance and suppress worker reproduction either by means of aggression (primarily in small colony species) or the emission of pheromone signals (van Zweden 2010; Kocher and Grozinger 2011), which helps to resolve this conflict. However, there is significant variation across species in the outcome of these queen-worker con- flicts over reproduction, which is reflected in large variation in the number of workers that reproduce, laying unfertilized maledestined eggs, even in the presence of the queen (Bourke 1988; Wenseleers and Ratnieks 2006a). A still ongoing debate (Keller 2009; Kocher and Grozinger 2011) is whether this variation reflects variable outcomes of a queen-worker arms race over reproduction, in which queens occasionally do not succeed in manipulating the workers to remain sterile ("queen control" hypothesis), or if instead there is variation in the workers' evolutionary incentive to respond to the queen's honest fertility signal and remain sterile ("queen signaling" hypothesis; reviewed in Keller and Nonacs 1993; Heinze and d'Ettorre 2009; Kocher and Grozinger 2011).

In putative support of the queen signaling hypothesis (Zahavi 1975; Keller and Nonacs 1993), several studies have identified cuticular hydrocarbon (CHC) cues that accurately reflect fertility in 
ants (e.g., Liebig et al. 2000; Cuvillier-Hot et al. 2004; de Biseau et al. 2004; D'Ettorre et al. 2004), termites (e.g., Liebig et al. 2009; Weil et al. 2009), and wasps (e.g., Sledge et al. 2001; Bhadra et al. 2010). In a few cases, there is also direct experimental evidence that workers actually respond to these fertility cues physiologically (D'Ettorre et al. 2004; Holman et al. 2010) and/or behaviorally (Endler et al. 2004; Smith et al. 2009; van Zweden et al. 2009; Holman et al. 2010), thereby supporting the role of particular CHCs as active queen- or fertility-signaling pheromones. Furthermore, in a few cases, intraspecific variation in the strength of the produced queen signals has also been linked to variation in the level of worker reproduction. In the ant Camponotus floridanus, for example, only workers of large established colonies effectively police eggs laid by other workers, but not in small incipient colonies. This was found to be due to the more pronounced chemical differences between queen- and worker-laid eggs in large colonies, where queens are more fecund, causing their eggs to contain relatively more fertility-linked hydrocarbons (Moore and Liebig 2010). A similar phenomenon was observed in Pachycondyla inversa (van Zweden et al. 2009), but here a lowered queen fertility and corresponding higher acceptance of worker-laid eggs was caused by moving colonies to laboratory conditions.

Whether these studies unambiguously support the queen signaling hypothesis (Zahavi 1975; Keller and Nonacs 1993) remains controversial, given that queen control is very hard to distinguish from queen signaling based solely on physiological evidence. Indeed, both hypotheses often result in identical predictions (Kocher and Grozinger 2011). For example, the discovery that queen mandibular pheromone (QMP), which suppresses worker reproduction in the honey bee, Apis mellifera, directly acts upon dopamine pathways in the worker brain (Beggs et al. 2007) has been suggested to be consistent with the queen control hypothesis. Yet, the fact that the workers as a collective also gain inclusive fitness benefits from remaining sterile (Wenseleers and Ratnieks 2006a) makes this observation consistent with queen signaling as well (Kocher and Grozinger 2011). Another example is the reversibility of the ovary development of honey bee workers observed after being reunited with the queen (Malka et al. 2007), which again is predicted under either hypothesis (Wenseleers and Ratnieks 2006a).

In our view, there are a few predictions that could more conclusively discriminate between the queen control and queen signaling hypotheses. First, a queen-worker arms race, which is expected under queen control, is predicted to result in rapid divergence of queen-specific compounds among related species (Keller and Nonacs 1993; Heinze and d'Ettorre 2009; Brunner et al. 2011). The idea is that if workers would indeed gain inclusive fitness by becoming reproductive, there should be selection for workers to evade the manipulation by building up tolerance to the queen pheromone, necessitating queens to perpetually produce new compounds to keep their daughters in check. This is similar to the coevolutionary arms race between males and females in Drosophila, which cause complex mixtures of seminal fluid proteins to be transferred to the female, some of which are detrimental to her fitness (Swanson et al. 2001; Findlay et al. 2008). By a similar argument, an arms race between the queens and workers would be expected to lead to species-specific and possibly complex mixtures of queen pheromones. Honest queen signaling, on the other hand, would be expected to result in slower evolution and hence in random or more conserved patterns of fertility-linked compounds across species. This is because the inclusive fitness of workers would be maximized by responding to this signal, thereby causing balancing selection on such signals.

Second, we can compare levels of worker ovary activation with theoretically predicted levels, which can be modeled for a species as a function of the average colony kin structure and the efficiency with which nestmates police worker-laid eggs (Wenseleers et al. 2004). Under the queen signaling hypothesis, workers in queenright colonies of a given species would be expected to reproduce according to this evolutionarily stable optimal proportion, where species with higher average sister-sister relatedness and lower policing efficiency are predicted to exhibit higher levels of worker reproduction. Under queen control, on the other hand, regardless of sister-sister relatedness very few reproductive workers would be expected. For queenless colonies the opposite pattern is expected: the queen signaling hypothesis predicts an evolutionarily stable optimum that is lower in species with higher sister-sister relatedness, whereas the queen control hypothesis would predict that most workers start reproducing regardless of the colony kin structure (Keller and Nonacs 1993; Wenseleers et al. 2004; Wenseleers and Ratnieks 2006b).

To test these predictions, we carried out a study on the Saxon wasp, Dolichovespula saxonica, where many workers activate their ovaries even in the presence of the queen (Foster and Ratnieks 2000; Bonckaert et al. 2011b). First, we examined to what extent information about queen fertility is encoded in her $\mathrm{CHC}$ profile and whether, at an intraspecific level, increased worker reproduction at later stages of colony development coincides with a decrease in the strength of the putative queen signals (see also Bonckaert et al. 2011b). If the queen's egg production decreases toward the end of the colony cycle, queen signals would be expected to decrease as well if they are honest signals of the queen's true fertility. Furthermore, workers are expected to respond to this by decreasing their policing behavior and increasing their reproduction, both because it is in their fitness interests to do so (cf. Ohtsuki and Tsuji 2009) and because discrimination between queen- and worker-laid eggs is likely to become harder 
(Moore and Liebig 2010). Second, we compared patterns of fertility-linked CHCs and worker reproduction of $D$. saxonica to those of Vespula vulgaris and several other Vespine wasps. This enabled us to assess the degree of evolutionary conservation of fertility-linked CHCs as well as to compare levels of worker reproduction against the theoretically predicted ones under a queen signaling framework (Wenseleers et al. 2004).

\section{Methods}

\section{STUDY SPECIES AND COLONY DEVELOPMENT}

Young queens of D. saxonica found their nests alone (and will remain the only queen) around mid May and the first workers emerge in early June. Maximally three to six combs are constructed throughout the colony's lifetime and the colony can reach up to 200-300 individuals. Colony development is relatively short and new queens and males can start emerging as early as the end of June, although this can be as late as mid August. At this point, the colony starts declining and eventually dies off, including the old queen. The virgin queens and males fly off to mate, after which only the queens remain to survive the winter by going into diapause.

Eight $D$. saxonica colonies containing a single queen, 40-195 workers, eggs, larvae, and pupae were collected on Zealand, Denmark, in July 2009 and frozen at $-20^{\circ} \mathrm{C}$ for further analysis. A Colony Stage parameter, bound between 0 (early stage) and 1 (final stage), was calculated for each colony by measuring comb size and dividing it by the predicted comb size when the colony would be completed (see also Bonckaert et al. 2011b).

\section{CHC ANALYSIS}

For each colony, we analyzed the CHC profiles of the queen $(n=8)$ and 33-40 workers $(n=303$, median $=38)$. Cuticular hydrocarbons were extracted by immersing single individuals in 1 ml HPLC-grade pentane (Sigma-Aldrich, Copenhagen, Denmark) for $10 \mathrm{~min}$. We let the pentane evaporate at room temperature and then resuspended the extract in $100 \mu l$ pentane, of which we injected $2 \mu \mathrm{l}$ in an Agilent 6890N gas chromatograph, equipped with a split-splitless injector set to splitless mode, an HP-5MS capillary column $(30 \mathrm{~m} \times 250 \mu \mathrm{m} \times 0.25 \mu \mathrm{m})$, helium carrier gas flow of $1 \mathrm{ml} \mathrm{min}{ }^{-1}$, and a flame ionization detector (FID). After an initial hold of $1 \mathrm{~min}$ at $70^{\circ} \mathrm{C}$, the temperature was raised to $210^{\circ} \mathrm{C}$ at a rate of $30^{\circ} \mathrm{C} \mathrm{min}{ }^{-1}$, then to $280^{\circ} \mathrm{C}$ at $3^{\circ} \mathrm{C} \mathrm{min}{ }^{-1}$, and then to $320^{\circ} \mathrm{C}$ again at $30^{\circ} \mathrm{C} \mathrm{min}{ }^{-1}$, with a final hold at $320^{\circ} \mathrm{C}$ of $5 \mathrm{~min}$. Peak areas of 56 hydrocarbons (or mixtures of coeluting hydrocarbons; Fig. S1) found on the cuticles of workers and queens were quantified using Agilent ChemStation (v. D.02.00.237). Components were identified by gas chromatography with mass spectrometry (GC-MS) using an Agilent $6890 \mathrm{~N}$ gas chromatograph coupled with an Agilent 5375 MS with elec- tron ionization (70eV; Fig. S1) (All equipment supplied by Agilent Technologies ApS, Glostrup, Denmark).

\section{OVARY DEVELOPMENT ASSESSMENT}

For each colony, all collected workers ( $n=820$, range $=40-195$, median $=100$ ) and the queen, which included all individuals used in the CHC analysis, were dissected to assess the state of their ovaries. Each individual was given an Ovary Score, where $0=$ undeveloped ovaries, 1 = ovary development below approximately $20 \%, 2=$ ovary development between approximately $20 \%$ and approximately 50\%, $3=$ ovary development between approximately 50\% and approximately 90\%, $4=$ completely developed ovaries. In addition, individuals were categorized according to their morphological and physiological status, Caste: queen (Q), reproductive workers (RW; Ovary Score $\geq 1$ ), or sterile worker $(\mathrm{SW}$; Ovary Score $=0)$. The percentage of RWs (\% RW) was calculated for each colony.

\section{GENOTYPING AND WORKER REPRODUCTION}

Male production by workers was estimated by genotyping 17-34 adult workers $(n=204$, median $=25)$ and 19-41 male pupae and adults $(n=291$, median $=39)$ per colony. Antennae or heads were frozen in liquid nitrogen, ground up and incubated at $95^{\circ} \mathrm{C}$ for $15 \mathrm{~min}$ in $200 \mu \mathrm{l}$ of a $10 \%$ Bio-Rad Chelex 100 resin solution (Bio-Rad Laboratories N.V., Nazareth Eke, Belgium). We used three microsatellite loci developed for Vespula rufa: Rufa05, Rufa13, and Rufa18 (Thorén et al. 1995). Polymerase chain reactions (PCRs) were performed in $10 \mu 1$ reactions using the Qiagen multiplex kit (Qiagen Benelux B.V., Venlo, Netherlands), with reactions containing $1 \mu \mathrm{l}$ of template DNA, $5 \mu 1$ master mix, $0.2 \mu 1$ of a $10 \mu \mathrm{M}$ solution of each primer, and $2.8 \mu$ l of Rnase-free $\mathrm{H}_{2} \mathrm{O}$. Primers were fluorescently labeled with VIC, PET ${ }^{\circledR}$, and 6-FAM (Applied Biosystems, Gent, Belgium). The PCR reaction cycle consisted of an initial denaturation at $95^{\circ} \mathrm{C}$ for $15 \mathrm{~min}$ followed by 30 cycles of $30 \mathrm{sec}$ at $95^{\circ} \mathrm{C}, 90 \mathrm{sec}$ at $50^{\circ} \mathrm{C}$, and $60 \mathrm{sec}$ at $72^{\circ} \mathrm{C}$, and a final extension of $30 \mathrm{~min}$ at $60^{\circ} \mathrm{C}$. Genotypes were assessed using internal Genescan 500 LIZ size standards (Applied Biosystems, Gent, Belgium) in an ABI-3130 Avant capillary sequencer and allele sizes were scored using GeneMapper software (Applied Biosystems, Gent, Belgium). The percentage of worker-produced males (\% WPM) was calculated as $W_{j} /\left(P_{j} N_{j}\right)$, where $W_{j}$ is the number of detected worker sons, $P_{j}$ the probability of detecting worker sons, and $N_{j}$ is the total number of males analyzed for the $j$ th nest, as in Foster and Ratnieks (2001).

\section{STATISTICAL ANALYSIS}

Principal component analysis (PCA) was based on integrated peak areas of $56 \mathrm{CHC}$ compounds from 311 individuals (Fig. 1). The $\mathrm{CHC}$ variables were first normalized using the transformation $y_{i j}$ $=\log \left(x_{i j} / g\left(X_{j}\right)\right)$ where $y_{i j}$ is the transformed peak area of the $i$ th CHC component of the $j$ th individual, $x_{i j}$ is the untransformed 


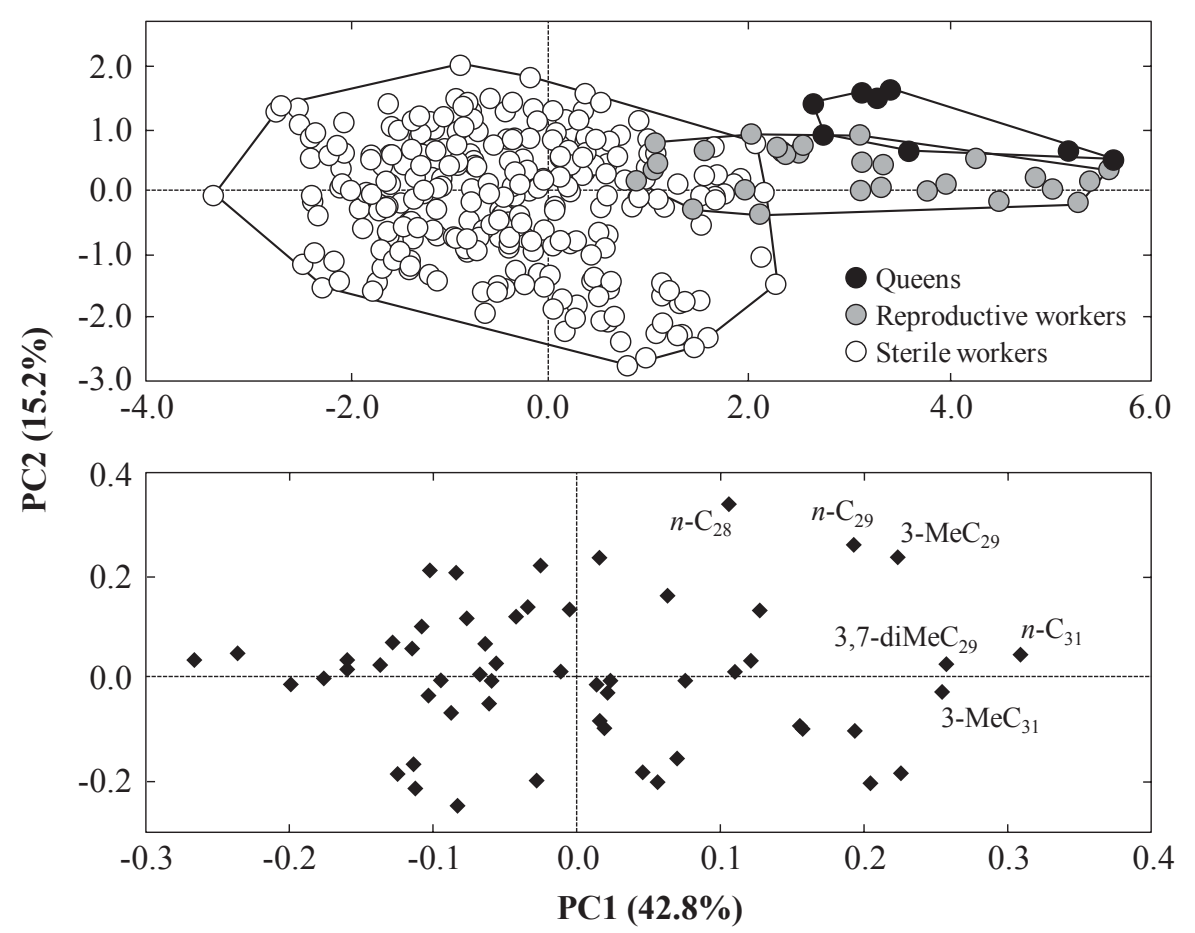

Figure 1. A PCA based on cuticular hydrocarbon (CHC) profiles of queens (Qs, $n=8)$, reproductive workers (RWs, $n=28)$, and sterile workers (SWs, $n=273$ ) of eight colonies of Dolichovespula saxonica. PC1 separates egg-laying (Qs and RWs) and non egg-laying individuals (SWs), whereas PC2 separates Qs and RWs. The lower panel shows the factor loadings and has six compounds highlighted that most strongly correlated with fertility (see also Fig. 3). PCA diagnostics are given in Table S1 and exact loadings are given in Table S2. Two outlier RWs with negative scores on PC1 were left out.

peak area of the $i$ th component of the $j$ th individual, and $g\left(X_{j}\right)$ is the geometric mean peak area of all components of the $j$ th individual (Aitchison 1986). Transformed peak areas were then mean-centered but not scaled to unit variance. Subsequent discriminant analyses (DAs) were performed with up to six principal components (PCs1-6) as variables, because the smallest group (Qs) had only eight individuals.

PC1 was regressed against Ovary Score, Colony Stage, \% RW, and \% WPM, using linear models and using the Akaike information criterion (AIC) to select among possible alternative models (Fig. 2). In the first two models, PC1 was entered as the dependent variable and Colony was included as a random variable. In the case of Ovary Score the best fit was a model without an interaction with the fixed variable Caste, whereas the interaction was significant in the case of Colony Stage. In the other two models, PC1 was entered as a fixed explanatory variable in interaction with Caste. Here, the random variable Colony was left out, because the dependent variables (\% RW, \% WPM) were colony-level traits so that Colony did not add any information. We corrected $P$ values for multiple testing using the Benjamini-Hochberg false discovery rate correction (Benjamini and Hochberg 1995).

To test the association between fertility and single $\mathrm{CHC}$ components, we used general linear mixed models, with 1000 Markov
Chain Monte Carlo simulations to estimate $P$ values (Fig. 3). Each of the 56 components was entered as a dependent variable, Colony was entered as a random effect and Caste $(\mathrm{Q}, \mathrm{RW}$, or $\mathrm{SW})$ as a fixed effect. Again, $P$ values were Benjamini-Hochberg corrected to control for multiple testing (Benjamini and Hochberg 1995) and we only regarded $P<0.01$ as being significant. This level of stringency was used because our variables are non-independent due to normalization to relative values. For effect-size measures of each $\mathrm{CHC}$ component, we sum-normalized to relative concentrations (\%) before calculating the $\log 2$ ratios for $\mathrm{Q}$ versus $\mathrm{SW}$ and $\mathrm{Q}$ versus RW (Fig. 3). All analyses were performed using R 2.14.0 (packages: FactoMineR, lme4, languageR) and MS Excel 2007.

\section{COMPARATIVE ANALYSIS OF VESPINE WASPS}

Data on $\log 2$ ratios between queen and worker $\mathrm{CHC}$ profiles were compared between $D$. saxonica and those of $V$. vulgaris (Bonckaert et al. 2012) and four other Vespine wasps (Butts et al. 1991; Fig. 2). Data on levels of RWs were compared between D. saxonica and V. vulgaris (Table 1) based on several studies (Table S3; Foster and Ratnieks 2000; Foster and Ratnieks 2001; Helanterä et al. 2006; Bonckaert et al. 2011b; J. S. van Zweden, W. Bonckaert, and T. Wenseleers, unpubl. data). 


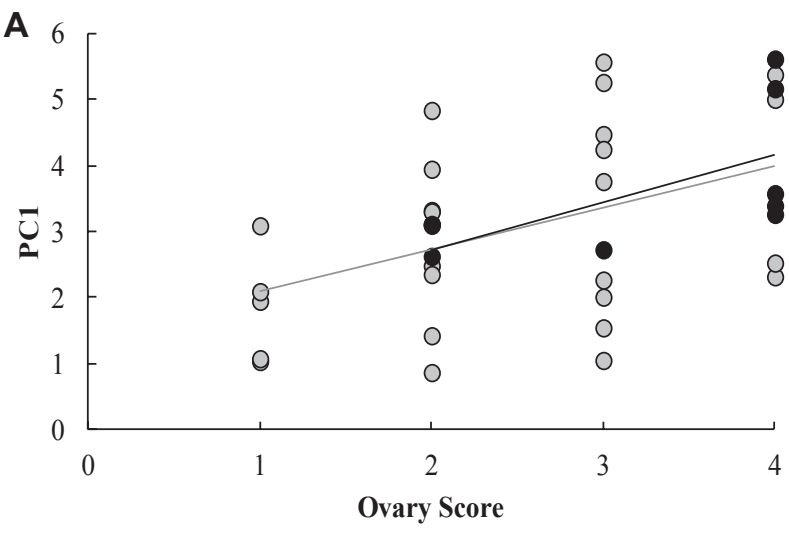

\begin{tabular}{lrrl}
\hline Variable & Estimate & $\mathbf{t}$ & $\mathbf{p}$ \\
\hline (Intercept) & 0.50 & 0.88 & 0.384 \\
Ovary Score & 0.89 & 5.81 & $<\mathbf{0 . 0 0 1} * * *$ \\
\hline
\end{tabular}

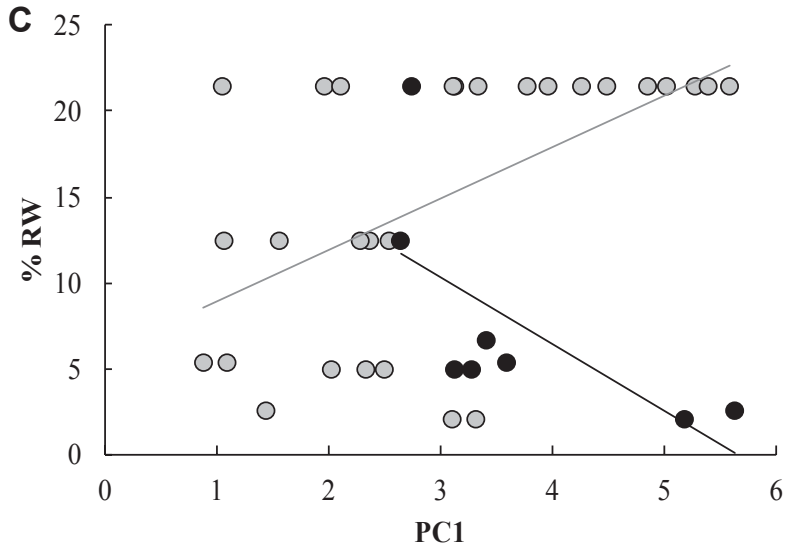

\begin{tabular}{lrrl}
\hline Variable & Estimate & $\mathbf{t}$ & $\mathbf{p}$ \\
\hline (Intercept) Q & 21.96 & 2.63 & $\mathbf{0 . 0 1 3}$ \\
$\mathrm{PC1}$ & -3.88 & -1.78 & 0.084 \\
Caste RW & -16.06 & -1.82 & 0.078 \\
$\mathrm{PC1}{ }^{*}$ Caste RW & 6.89 & 2.95 & $\mathbf{0 . 0 0 6} * *$ \\
\hline
\end{tabular}

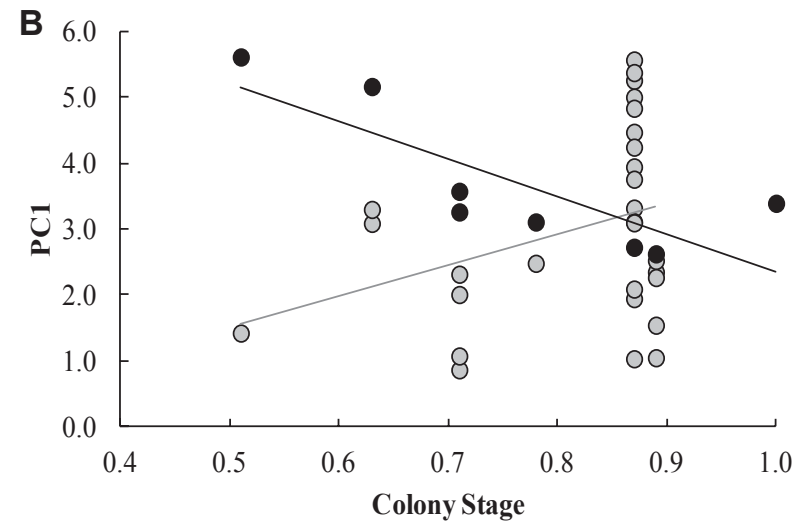

\begin{tabular}{lrrl}
\hline Variable & Estimate & t & p \\
\hline (Intercept) Q & 8.03 & 3.26 & $\mathbf{0 . 0 0 3} * *$ \\
Colony Stage & -5.68 & -1.79 & 0.083 \\
Caste RW & -8.47 & -3.02 & $\mathbf{0 . 0 0 5} * *$ \\
Colony Stage * Caste RW & 9.62 & 2.67 & $\mathbf{0 . 0 1 2} *$ \\
\hline
\end{tabular}

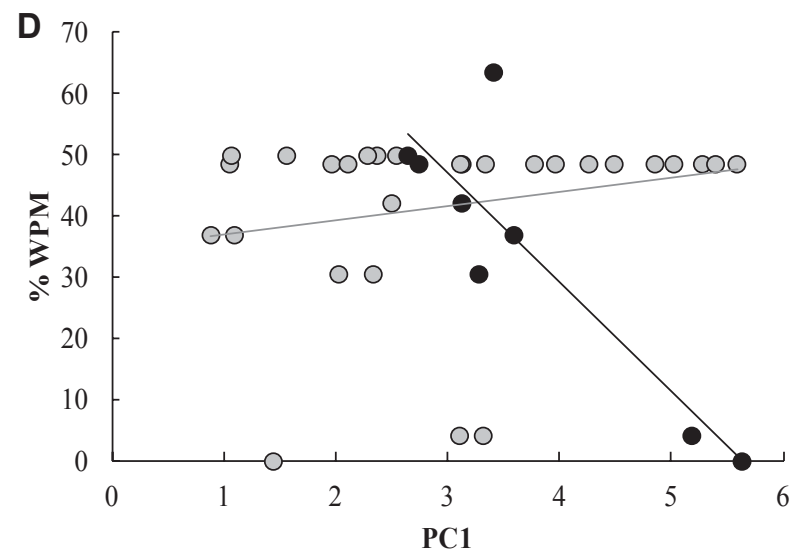

\begin{tabular}{lrrl}
\hline Variable & Estimate & \multicolumn{1}{l}{ t } & p \\
\hline (Intercept) Q & 100.66 & 5.44 & $<\mathbf{0 . 0 0 1} * * *$ \\
PC1 & -17.87 & -3.71 & $<\mathbf{0 . 0 0 1} * * *$ \\
Caste RW & -65.97 & -3.38 & $\mathbf{0 . 0 0 2} * *$ \\
PC1 $*$ Caste RW & 20.17 & 3.90 & $<\mathbf{0 . 0 0 1} * * *$ \\
\hline
\end{tabular}

Figure 2. The scores of queens (Qs; black dots; $\boldsymbol{n}=\mathbf{8}$ ) and reproductive workers (RWs; gray dots; $\boldsymbol{n}=28$ ) on the fertility-associated axis PC1 (see Fig. 1) regressed against (A) their Ovary Score, and (B) the stage at which colonies were in their development (Colony Stage). (C) The percentage of RWs in their colonies (\% RW), and (D) the percentage of worker-produced males in their colonies (\% WPM) regressed against PC1 scores. Two outlier RWs with negative scores on PC1 were left out.

Evolutionary stable optimum levels of worker reproduction were calculated using formula 1.8 and 2.8 in Wenseleers et al. (2004; Supporting Information Methods; Tables S3-S5; Fig. S2). This formula calculates the evolutionarily stable strategy (ESS) proportion of laying workers per colony as a function of colony size, the relative survival of worker-laid eggs compared to queen-laid eggs, the effect of worker reproduction on colony productivity, species-level average sister-sister relatedness, and the relative fecundity of the queen compared to workers in terms of male eggs (see further details in Supporting Information).

\section{Results}

\section{FERTILITY-LINKED CHCS OF DOLICHOVESPULA SAXONICA}

We identified 55 of the $56 \mathrm{CHC}$ peaks found on the cuticles of all individuals (Fig. S1), which we used as variables in a PCA (see Table $\mathrm{S} 1$ for diagnostic details). We found a clear distinction between the reproductive castes Qs, RWs, and SWs (Fig. 1), and each of PCs 1-5 could discriminate among both colonies and reproductive castes (Table S1). In a DA based on PCs 1-6, we could 


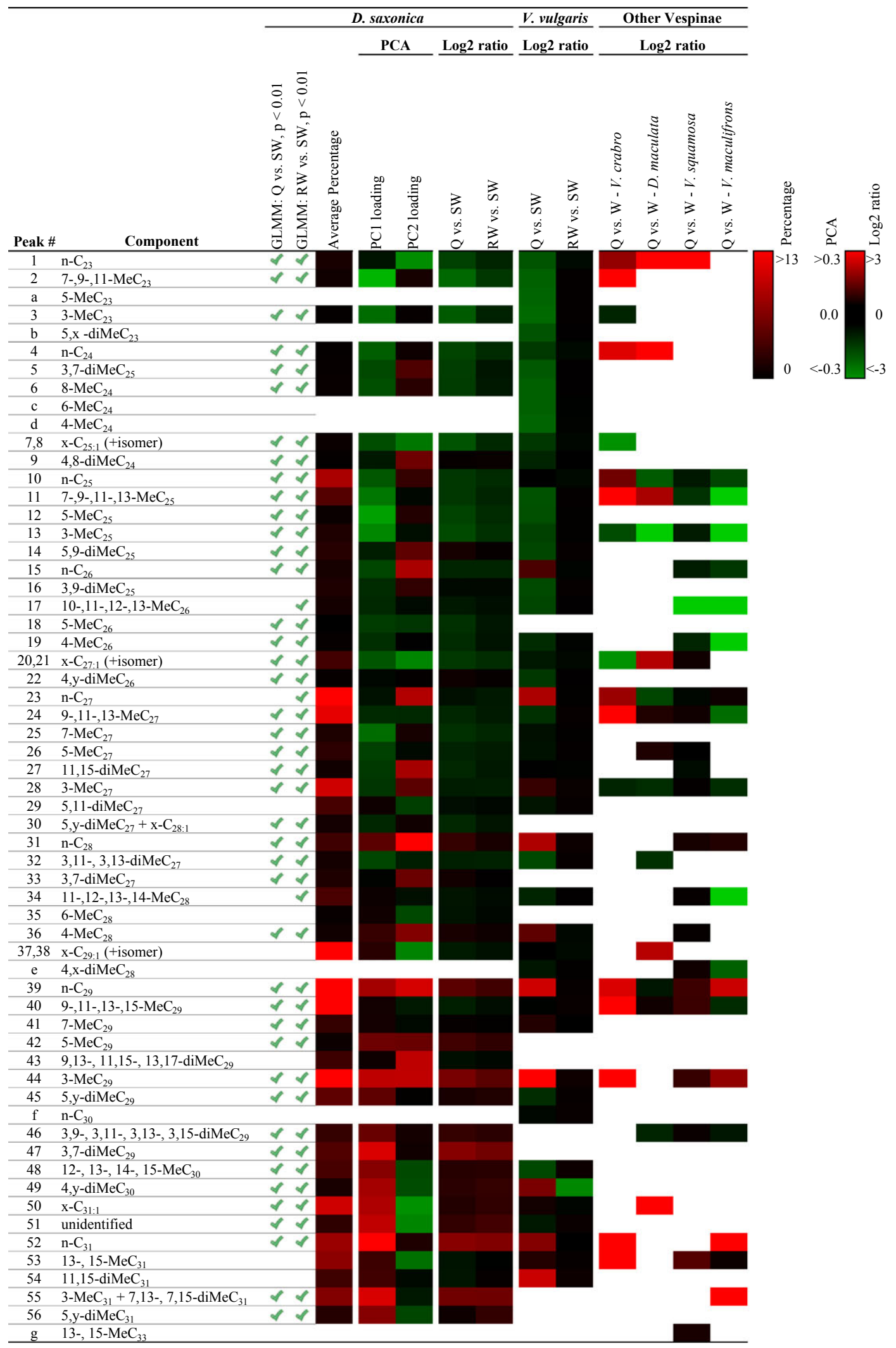

Figure 3. Heat map of how components of the cuticular hydrocarbon (CHC) profile correlate with fertility in Dolichovespula saxonica, Vespula vulgaris, and other Vespinae (red = positive values, green = negative values, black = zero). Exact values are given in Table S2. Details of the GLMM and PCA are given in the text. Log2 ratios are calculated as the $\log _{2}$ of the ratio of the means. References for $V$. vulgaris (Bonckaert et al. 2012), Vespa crabro, D. maculata, Vespula squamosa, and Vespula maculifrons (Butts et al. 1991). The color version of this figure only appears online. 
Table 1. Data on the average colony kin structure, the presence or absence of policing by the queen or workers and the observed and predicted (evolutionarily stable) percentage of reproductive workers in queenright and queenless colonies of the two Vespine wasps, Dolichovespula saxonica and Vespula vulgaris (see Supporting Information Methods), where chemical fertility cues have been characterized in detail. Sample sizes (colonies) are shown in brackets.

\begin{tabular}{|c|c|c|c|}
\hline & D. saxonica & V. vulgaris & References \\
\hline $\begin{array}{l}\text { Effective queen mating frequency } \\
\text { (number of colonies) }\end{array}$ & $1.4(35)$ & $1.9(17)$ & $\begin{array}{l}\text { Bonckaert et al. (2011b), Foster and } \\
\text { Ratnieks (2000), Foster and } \\
\text { Ratnieks (2001) }\end{array}$ \\
\hline $\begin{array}{l}\text { Worker-worker relatedness } \\
\text { (number of colonies) }\end{array}$ & $0.61(35)$ & $0.51(17)$ & $\begin{array}{l}\text { Bonckaert et al. (2011b), Foster and } \\
\text { Ratnieks (2000), Foster and } \\
\text { Ratnieks (2001) }\end{array}$ \\
\hline $\begin{array}{l}\text { Average colony size in terms of } \\
\text { workers (number of colonies) }\end{array}$ & $113(25)$ & $2042(46)$ & $\begin{array}{l}\text { Bonckaert et al. (2011b), Helanterä et } \\
\text { al. (2006) }\end{array}$ \\
\hline Queen policing present? & Yes & No & $\begin{array}{l}\text { Foster and Ratnieks (2001), T. } \\
\text { Wenseleers, unpubl. data }\end{array}$ \\
\hline Worker policing present? & Perhaps $^{1}$ & Yes & $\begin{array}{l}\text { Bonckaert et al. (2011b), Foster and } \\
\text { Ratnieks (2000), Foster and } \\
\text { Ratnieks (2001) }\end{array}$ \\
\hline Effectiveness of policing ${ }^{2}$ & 0.88 & $0.99-1^{3}$ & $\begin{array}{l}\text { Reviewed in Wenseleers and Ratnieks } \\
\text { (2006a) }\end{array}$ \\
\hline $\begin{array}{l}\text { Observed \% RW in queenright } \\
\text { colonies (number of colonies) }\end{array}$ & $6.5 \%(22)$ & $1.0 \%(6)$ & Table S3 \\
\hline $\begin{array}{l}\text { Expected ESS \% RW in queenright } \\
\text { colonies }^{4}\end{array}$ & $7.9 \%$ & $0.0 \%$ & $\begin{array}{l}\text { Supporting Information Methods; } \\
\text { Wenseleers et al. (2004) }\end{array}$ \\
\hline $\begin{array}{l}\text { Observed \% RW in queenless } \\
\text { colonies (number of colonies) }\end{array}$ & $10.0 \%(19)$ & $29.7 \%(10)$ & Table S3 \\
\hline $\begin{array}{l}\text { Expected ESS \% RW in queenless } \\
\text { colonies }{ }^{4}\end{array}$ & $16.9 \%$ & $23.4 \%$ & $\begin{array}{l}\text { Supporting Information Methods; } \\
\text { Wenseleers et al. (2004) }\end{array}$ \\
\hline
\end{tabular}

${ }^{1}$ Foster and Ratnieks (2000) and Bonckaert et al. (2011b) provided evidence that the proportion worker-laid eggs and the proportion worker-produced males surviving to adulthood differ significantly, but there was no direct behavioral data on worker policing. Behavioral data from other Dolichovespula species have shown that although workers sometimes cannibalize worker-laid eggs, this policing is not very effective, because these workers often lay eggs themselves (Bonckaert et al. 2011a; Wenseleers et al. 2005).

${ }^{2}$ Defined as $\left(1-S_{w}\right)$, where $S_{w}$ is the probability that worker-laid eggs survive to adulthood relative to queen-laid eggs (Wenseleers et al. 2004).

${ }^{3}$ In policing bioassays all of the 120 introduced worker-laid eggs were removed within $16 \mathrm{~h}$, which would imply a policing efficiency of 1 . Nevertheless, a more extensive study on the related species Vespula germanica has estimated the effectiveness of policing at 0.99 (Bonckaert et al. 2008 ), and this is probably also quite a realistic estimate for $V$. vulgaris.

${ }^{4}$ Predicted evolutionarily stable percentage of reproductive workers in queenright and queenless colonies, as described in the Methods S1.

classify $95.5 \%$ of the individuals correctly (overall: 297/311; Qs: 5/8 [=62.5\%], RWs: 21/30 [=70.0\%], SWs: 271/273 [=99.3\%]). Using PCs 1 and 2 alone, however, already resulted in a strong discrimination among the individuals belonging to different reproductive castes, with $\mathrm{PC} 1$ separating reproductives (Qs and RWs) from nonreproductives (SWs; analysis of variance [ANOVA], $\left.F_{1,309}=254.42, P<0.001\right)$ and PC2 discriminating between Qs and RWs $\left(F_{1,36}=23.90, P<0.001\right)$. A DA based on PCs 1 and 2 alone could correctly classify $93.6 \%$ of the individuals (overall: 291/311; Qs: 2/8 (=25.0\%), RWs: 18/30 (=60.0\%), SWs: $271 / 273$ (=99.3\%). Incorrectly classified Qs and SWs were in all cases classified as RWs instead, whereas two incorrect RWs were consistently classified as Qs and the rest as SWs.
We found a positive relationship between the fertility-linked PC1 and the ovary development (Ovary Score) for both Qs and RWs, with the effect being comparable in the two castes (Fig. 2A). Interestingly, the PC1 score of Qs also decreased at later stages of colony development, whereas the opposite was true for RWs (Fig. 2B). For Q, PC1 also had a negative relationship with the $\%$ RW (Fig. 2C) and the \% WPM (; Fig. 2D), but these relationships were positive for RWs, if anything. This parallels the decrease in queen fecundity and increase in levels of worker reproduction observed near the end of colony development (Bonckaert et al. 2011b).

PC1 was strongly associated with $\mathrm{CHC}$ chain length. Nearly all compounds with a backbone of 28 or more carbon atoms had positive loadings and those with less than 28 had negative 
factor loadings. The alkane compounds $n-\mathrm{C}_{31}, 3-\mathrm{MeC}_{31}$, and 3,7diMeC $_{29}$ had the highest positive loadings (Figs. 1 and 3; Table $\mathrm{S} 2$ ) and thus distinguished reproductive from non-reproductive individuals. PC2 gave high loadings for the alkanes $n-\mathrm{C}_{28}, n-\mathrm{C}_{29}$, and $3-\mathrm{MeC}_{29}$, which thus were more characteristic for Qs than for RWs, whereas all the unsaturated hydrocarbons (alkenes) loaded most negatively on PC2 (Fig. 3; Table S2). Correspondingly, the $\log 2$ ratios further confirmed that $n-\mathrm{C}_{31}, 3,7-\mathrm{diMeC}_{29}, 3-\mathrm{MeC}_{29}$, $3-\mathrm{MeC}_{31}$, and $n-\mathrm{C}_{29}$ were most strongly increased in both Qs and RWs relative to SWs (Fig. 3; Table S2).

\section{COMPARATIVE ANALYSIS OF VESPINE WASPS}

When we compared $D$. saxonica to other Vespine wasps, we found that several $\mathrm{CHCs}$ are consistently increased in Qs relative to workers (Ws) across species (Fig. 3). In particular, the species $V$. vulgaris, Vespa crabro, and Vespula maculifrons (and to a certain extent Vespula squamosa as well) show higher abundance of the alkanes $n-\mathrm{C}_{29}, 3-\mathrm{MeC}_{29}$, and $n-\mathrm{C}_{31}$ on Qs compared to Ws. In $D$. maculata, however, the alkenes are characteristic of the $\mathrm{Q}$ profile (Fig. 3). When comparing only D. saxonica and V. vulgaris, we find that for the former $\mathrm{Q}$ and RW profiles are very similar to each other, meaning that in $D$. saxonica $\mathrm{CHC}$ profiles are mostly fertility linked, whereas in $V$. vulgaris profiles of RWs are very similar to those of SWs, meaning that CHC profiles are mostly caste specific and have a much weaker link with fertility (Fig. 3). Nonetheless, there is a significant correlation between the fertilitylinked compounds found on Qs and RWs of D. saxonica and the Q-specific profiles of $V$. vulgaris (Spearman rank correlation of $\log 2$ ratios of overlapping compounds, D. saxonica $\mathrm{Q} / \mathrm{SW}$ vs. $V$. vulgaris $\mathrm{Q} / \mathrm{SW}, \rho=0.614$, degrees of freedom $[\mathrm{df}]=41, P$ $<0.001 ;$ D. saxonica $\mathrm{RW} / \mathrm{SW}$ vs. $V$. vulgaris $\mathrm{Q} / \mathrm{SW}, \rho=0.472$, df $=41, P=0.001$ ), showing a significant conservation of the expression levels of these cues/signals across the two species. The data of other Vespine species were not statistically compared with $D$. saxonica and $V$. vulgaris, because the data were obtained with too divergent methods and machinery and, as far as we are aware, there is currently no species-level calibrated phylogeny available to correct for phylogenetic non-independence. Visual inspection, however, also indicates high abundance of $n-\mathrm{C}_{29}$ and 3 $\mathrm{MeC}_{29}$ on queens compared to workers in V. crabro, V. squamosa, and $V$. maculifrons, thereby reinforcing the idea of phylogenetic conservation of queen-specific cues across Vespine wasps.

Levels of worker reproduction of D. saxonica and V. vulgaris were found to fit well with theoretically predicted values as expected under the queen signaling hypothesis (Table 1; Supporting Information Methods; Tables S3-S5; Fig. S2). Dolichovespula saxonica shows a higher species-level average sister-sister relatedness and lower policing efficiency, and observed values of worker reproduction were higher for $D$. saxonica than for
$V$. vulgaris in queenright colonies (6.5 vs. $1.0 \%)$, whereas the opposite was true for queenless colonies (10.0 vs. $29.7 \%)$.

\section{Discussion}

Our results demonstrate that fertile and sterile individuals of the Saxon wasp, D. saxonica, can be reliably distinguished based on their CHC profiles. Particular CHCs that load high on the first principal axis of variation moreover correlate well with the queens' levels of ovary development, and the relative abundance of these fertility-linked CHCs decreases and worker reproduction increases with the development of their colonies. Next, when comparing fertility-linked CHCs of D. saxonica to those of $V$. vulgaris and other Vespine wasps, we found similar components to be increased in queens compared to workers across species. Finally, we found that levels of worker reproduction in $D$. saxonica and $V$. vulgaris followed the prediction of the queen signaling hypothesis, with workers reproducing according to their own best inclusive fitness interests. In particular, in $D$. saxonica, where nestmates are on average more related to each other and policing of worker-laid eggs is less efficient, there is a smaller difference in worker reproduction between queenright and queenless colonies. Therefore, all lines of evidence point toward the validity of the queen signaling hypothesis in $D$. saxonica wasps.

The CHCs that were most specific of queens and reproductive workers in D. saxonica, and thus appeared mostly fertility-linked, were several 3-(di)methyl and linear alkanes of long chain length: $n-\mathrm{C}_{29}, 3-\mathrm{MeC}_{29}, 3,7-\mathrm{diMeC}_{29}, n-\mathrm{C}_{31}$, and 3-MeC 31 . Among these, the compounds $n-\mathrm{C}_{29}, 3-\mathrm{MeC}_{29}$, and $n-\mathrm{C}_{31}$ are also queen-specific in most of the other Vespine wasps investigated here (Fig. 3), as well as, for example, in the wasp Polistes dominulus (Sledge et al. 2004) and in the ant P. inversa (van Zweden et al. 2009). On the other hand, different compounds have been observed to correlate with fertility in other social Hymenopteran species (e.g., Monnin et al. 1998; Liebig et al. 2000; Smith et al. 2008). Reproductive individuals of $D$. saxonica generally also appear to shift to longer $\mathrm{CHC}$ chain lengths compared to non-reproductives (Fig. 3). Such shifts to longer or shorter chain length in relation to fertility have also been observed in other ants and wasps (e.g., Liebig et al. 2000; Hannonen et al. 2002; van Zweden et al. 2009; Moore and Liebig 2010; Bonckaert et al. 2012;), suggesting that some of the physiological pathways involved in the production of fertilitylinked CHCs are conserved across species. From a biochemical point of view, chain length specificity is, at least in Dipteran species, controlled by a fatty acyl-CoA elongase reaction, which in turn is influenced by ecdysteroid hormones produced by the female ovaries and fat bodies (Chertemps et al. 2007; Blomquist 2010). Cuticular hydrocarbon fertility cues in these species thus appear to arise as a by-product of the shuttling of hydrocarbons 
to the ovaries. Similar ecdysteroid hormones, and genes involved in the production thereof, are produced in developed A. mellifera ovaries and fat bodies (Robinson et al. 1991; Yamazaki et al. 2011), so that the resulting expression of CHC patterns, even if simple by-products of ovary development, could be co-opted to function as an honest signal and mediate reproductive division of labor in social insects.

Dolichovespula species are characterized by a high percentage of reproductive workers in queenright colonies (D. norwegica, Bonckaert et al. 2011a; D. saxonica, Bonckaert et al. 2011b; D. sylvestris, Wenseleers et al. 2005). This pattern of worker reproduction appears strong in species with annual life cycles, such as Vespine wasps and bumble bees (Duchateau and Velthuis 1988), although the eventual percentage of worker-produced males varies considerably across species and across stages of colony development (Alaux et al. 2004; Wenseleers and Ratnieks 2006a). In a previous study of the same population but with a more extended dataset, we observed that colony development was a strong determinant for the proportion of worker-produced males (Bonckaert et al. 2011b), which is in line with the notion that there should be less worker reproduction and more worker policing in the early ergonomic stages of the colony (Ohtsuki and Tsuji 2009). Indeed, workers may gain fitness benefits by increasing their own reproduction and decreasing efforts toward policing the reproduction of other workers when enough new queens have been produced, when the production of males has started, or the queen's fecundity has dropped due to old age (Alaux et al. 2004; Ohtsuki and Tsuji 2009). Therefore, we expect that worker responses to cues, whether directly from the queen or not, that allude to such an increase in inclusive fitness are selected for among most social Hymenoptera, but are most easily observed in annual species such as those of Vespinae and Bombini.

The correlational evidence in this study suggests that the increase in worker reproduction as a function of colony development is caused by the decreasing fecundity of the queen and the consequential decrease in the queen's CHC fertility signal, which in turn can inform the workers when to start developing their ovaries (Fig. 2). Alternatively, the CHC profiles of $D$. saxonica individuals could simply reflect their reproductive status, without necessarily functioning as informative signals. In this case, workers could, for example, simply be responding to environmental change using a different set of queen-derived or environmental cues that we did not investigate. Under this scenario, we might observe a similar pattern as when the CHCs do function as informative signals. However, we deem this unlikely, as we now have evidence from the related species $V$. vulgaris that the $\mathrm{CHCs}$ most characteristic for queens can induce worker sterility, suggesting that these compounds do indeed act as queen signaling pheromones (van Oystaeyen et al., unpubl. ms.). Based on this, it is therefore reasonable to assume that queen-specific $\mathrm{CHCs}$ are also informative signals central in the regulation of division of labor in D. saxonica.

Comparison of $\mathrm{CHC}$ patterns among the different Vespine species indicates that there is strong conservation of the queenspecific compounds between these species, arguing for the validity of the queen signaling hypothesis in social wasps (cf. Keller and Nonacs 1993; Heinze and d'Ettorre 2009). Similar to Lasius ants, where 3-methyl alkanes characterize the queens' cuticular profiles and in at least two species have a proven function as queen signal (Holman et al. 2013), the linear and 3-methyl alkanes are generally characteristic for queens in the species studied so far in the genera Dolichovespula, Vespula, and Vespa (with the notable exception of $D$. maculata). Focusing only on $D$. saxonica and $V$. vulgaris, we further notice that, whereas in the first species $\mathrm{CHC}$ differences are most strongly linked to differences in fertility, similar compounds show caste-specific differences in the latter species (Fig. 3). This means that in D. saxonica the difference lies in the fertility of an individual, almost regardless of it being a worker or a queen, whereas in $V$. vulgaris the difference lies more in the caste of an individual, regardless of their fertility. This is in line with the greater queen-worker size dimorphism observed in $V$. vulgaris (Wenseleers and Ratnieks 2006b) and argues for the evolution of "queen signals" through co-option of pre-existing "fertility cues," assuming at least that $D$. saxonica represents the more primitive state. This is interesting, especially considering the idea that $\mathrm{CHCs}$ are produced as mere by-products of the shuttling of hydrocarbons toward developing oocytes (see also Smith et al. 2009; Blomquist 2010). What it could mean is that while in a species such as D. saxonica the $\mathrm{CHC}$ profile is a direct index of an individual's fertility, the CHCs and ovary development of $V$. vulgaris became decoupled and the former could evolve to become a proper signal, with the possibility of individuals hiding or exaggerating their fertility status and/or a different evolutionary mechanism to ensure the signal's honesty. These inferences still require further testing, both at a molecular level and in a phylogenetic setting using a more complete dataset of the pheromone profiles of different eusocial species and their reproductive castes.

Lastly, the level of worker reproduction in $V$. vulgaris shows a much larger difference between queenright and queenless colonies than in $D$. saxonica, in line with the queen signaling hypothesis rather than queen control, because this pattern follows the workers' optimum given their differences in species-level average sister-sister relatedness and policing efficiency (Table 1; Wenseleers et al. 2004; Wenseleers and Ratnieks 2006b). An earlier test, based on the comparison of levels of worker reproduction in nine species of Vespine wasps and the honey bee, provided similar support for the queen signaling hypothesis (Wenseleers and Ratnieks 2006b). In particular, fewer workers attempted to reproduce in queenright colonies of species with low average 
sister-sister relatedness, because of the stronger selection to effectively police each others' eggs (Ratnieks 1988; Ratnieks et al. 2006), thereby supporting the idea that workers respond to queen signals in their own best interest (Keller and Nonacs 1993; Kocher and Grozinger 2011). To conclude, our study provides several lines of evidence showing that the queen signaling hypothesis is the most parsimonious hypothesis to explain levels of reproductive division of labor in social wasps, thereby helping to resolve a long-standing controversy in evolutionary sociobiology.

\section{ACKNOWLEDGMENTS}

We are grateful to K.R. Foster for providing us with the original data of his studies of Vespine wasps and to all members of the Copenhagen Centre for Social Evolution for providing a stimulating working environment. JSvZ and PdE were supported by a postdoctoral fellowship from the Danish Council for Independent Research (FNU 09-066595) and an EU Marie Curie Excellence Grant CODICES-EXT-CT-2004-014202. WB and TW were supported by the Institute for the Promotion of Innovation through Science and Technology in Flanders (IWT-Vlaanderen), the Research Foundation Flanders (FWO GNM-B5996-KAN2006), and the Centre of Excellence funding by the KU Leuven Research Fund (PF/2010/007).

\section{DATA ARCHIVING}

All data on cuticular hydrocarbons, reproductive status of individuals and colony parameters is available from the Dryad Digital Repository: doi:10.5061/dryad.2t8r1.

\section{LITERATURE CITED}

Aitchison, J. 1986. The statistical analysis of compositional data. The Blackburn Press, Caldwell, NJ.

Alaux, C., F. Savarit, P. Jaisson, and A. Hefetz. 2004. Does the queen win it all? Queen-worker conflict over male production in the bumblebee, Bombus terrestris. Naturwissenschaften 91:400-403.

Beggs, K. T., K. A. Glendining, N. M. Marechal, V. Vergoz, I. Nakamura, K. N. Slessorf, and A. R. Mercer. 2007. Queen pheromone modulates brain dopamine function in worker honey bees. Proc. Natl. Acad. Sci. USA 104:2460-2464.

Benjamini, Y., and Y. Hochberg. 1995. Controlling the false discovery rate: a practical and powerful approach to multiple testing. J. R. Stat. Soc. Ser. B Stat. Methodol. 57(1):289-300.

Bhadra, A., A. Mitra, S. Deshpande, K. Chandrasekhar, D. Naik, A. Hefetz, and R. Gadagkar. 2010. Regulation of reproduction in the primitively Eusocial Wasp Ropalidia marginata: on the trail of the queen pheromone. J. Chem. Ecol. 36(4): 424-431.

Blomquist, G. J. 2010. Biosynthesis of cuticular hydrocarbons. Pp. 35-52 in G. J. Blomquist and A. G. Bagnères, eds. Insect hydrocarbons: biology, biochemistry, and chemical ecology. Cambridge Univ. Press, New York.

Bonckaert, W., F. P. Drijfhout, P. d'Ettorre, J. Billen, and T. Wenseleers. 2012. Hydrocarbon signatures of egg maternity, caste membership and reproductive status in the common wasp. J. Chem. Ecol. 38:42-51.

Bonckaert, W., A. Tofilski, F. S. Nascimento, J. Billen, F. L. W. Ratnieks, and T. Wenseleers. 2011a. Co-occurrence of three types of egg-policing in the Norwegian wasp Dolichovespula norwegica. Behav. Ecol. Sociobiol. 65:633-640.

Bonckaert, W., J. S. van Zweden, P. d'Ettorre, J. Billen, and T. Wenseleers. 2011b. Colony stage and not facultative policing explains pattern of worker reproduction in the Saxon wasp. Mol. Ecol. 20(16):3455-3468.
Bonckaert, W., K. Vuerinckx, J. Billen, R. L. Hammond, L. Keller, and T. Wenseleers. 2008. Worker policing in the German wasp Vespula germanica. Behav. Ecol. 19(2):272-278.

Bourke, A. F. G. 1988. Worker reproduction in the higher eusocial Hymenoptera. Q. Rev. Biol. 63(3):291-311.

- 2011. Principles of social evolution. Oxford Univ. Press, New York.

Brunner, E., J. Kroiss, A. Trindl, and J. Heinze. 2011. Queen pheromones in Temnothorax ants: control or honest signal? BMC Evol. Biol. 11:55.

Butts, D. P., K. E. Espelie, and H. R. Hermann. 1991. Cuticular hydrocarbons of four species of social wasps in the subfamily vespinae: Vespa crabro (L.), Dolichovespula maculata (L.), Vespula squamosa (Drury), and Vespula maculifrons (Buysson). Comp. Biochem. Physiol. B 99:8791.

Chertemps, T., L. Duportets, C. Labeur, R. Ueda, K. Takahashi, K. Saigo, and C. Wicker-Thomas. 2007. A female-biased expressed elongase involved in long-chain hydrocarbon biosynthesis and courtship behavior in Drosophila melanogaster. Proc. Natl. Acad. Sci. USA 104:42734278.

Cuvillier-Hot, V., A. Lenoir, R. Crewe, C. Malosse, and C. Peeters. 2004. Fertility signalling and reproductive skew in queenless ants. Anim. Behav. 68:1209-1219.

de Biseau, J.-C., L. Passera, D. Daloze, and S. Aron. 2004. Ovarian activity correlates with extreme changes in cuticular hydrocarbon profile in the highly polygnous ant, Linepithema humile. J. Insect Physiol. 50:585593.

D'Ettorre, P., J. Heinze, C. Schulz, W. Francke, and M. Ayasse. 2004. Does she smell like a queen? Chemoreception of a cuticular hydrocarbon signal in the ant Pachycondyla inversa. J. Exp. Biol. 207(Pt 7): 1085-1091.

Duchateau, M. J., and H. H. W. Velthuis. 1988. Development and reproductive strategies in Bombus terrestris colonies. Behaviour 107:186-207.

Endler, A., J. Liebig, T. Schmitt, J. E. Parker, G. R. Jones, P. Schreier, and B. Hölldobler. 2004. Surface hydrocarbons of queen eggs regulate worker reproduction in a social insect. Proc. Natl. Acad. Sci. USA 101:29452950.

Findlay, G. D., X. Yi, M. J. MacCoss, and W. J. Swanson. 2008. Proteomics reveals novel Drosophila seminal fluid proteins transferred at mating. PLoS Biol. 6:e178.

Foster, K. R., and F. L. W. Ratnieks. 2000. Facultative worker policing in a wasp. Nature 407:692-693.

. 2001. Convergent evolution of worker policing by egg eating in the honeybee and common wasp. Proc. R. Soc. B Biol. Sci. 268:169174.

Hannonen, M., M. F. Sledge, S. Turillazzi, and L. Sundström. 2002. Queen reproduction, chemical signalling and worker behaviour in polygyne colonies of the ant Formica fusca. Anim. Behav. 64:477-485.

Heinze, J., and P. d'Ettorre. 2009. Honest and dishonest communication in social Hymenoptera. J. Exp. Biol. 212:1775-1779.

Helanterä, H., A. Tofilski, T. Wenseleers, and F. L. W. Ratnieks. 2006. Worker policing in the common wasp Vespula vulgaris is not aimed at improving colony hygiene. Insect. Soc. 53:399-402.

Holman, L., C. G. Jørgensen, J. Nielsen, and P. d'Ettorre. 2010. Identification of an ant queen pheromone regulating worker sterility. Proc. Roy. Soc. B 277:3793-3800.

Holman, L., R. Lanfear, and P. d'Ettorre. 2013. The evolution of queen pheromones in the ant genus Lasius. J. Evol. Biol. 26:1549-1558.

Keller, L. 2009. Adaptation and the genetics of social behaviour. Philos. Trans. R. Soc. B Biol. Sci. 364:3209-3216.

Keller, L., and P. Nonacs. 1993. The role of queen pheromones in social insects: queen control or queen signal? Anim. Behav. 45:787-794.

Kocher, S., and C. Grozinger. 2011. Cooperation, conflict, and the evolution of queen pheromones. J. Chem. Ecol. 37:1263-1275. 
Liebig, J., D. Eliyahu, and C. S. Brent. 2009. Cuticular hydrocarbon profiles indicate reproductive status in the termite Zootermopsis nevadensis. Behav. Ecol. Sociobiol 63:1799-1807.

Liebig, J., C. Peeters, N. J. Oldham, C. Markstadter, and B. Hölldobler. 2000. Are variations in cuticular hydrocarbons of queens and workers a reliable signal of fertility in the ant Harpegnathos saltator? Proc. Natl. Acad. Sci. USA 97:4124-4131.

Malka, O., S. Shnieor, A. Hefetz, and T. Katzav-Gozansky. 2007. Reversible royalty in worker honeybees (Apis mellifera) under the queen influence. Behav. Ecol. Sociobiol. 61:465-473.

Monnin, T., C. Malosse, and C. Peeters. 1998. Solid-phase microextraction and cuticular hydrocarbon differences related to reproductive activity in queenless ant Dinoponera quadriceps. J. Chem. Ecol. 24: 473-490.

Moore, D., and J. Liebig. 2010. Mechanisms of social regulation change across colony development in an ant. BMC Evol. Biol. 10:328.

Ohtsuki, H., and K. Tsuji. 2009. Adaptive Reproduction schedule as a cause of worker policing in social Hymenoptera: a dynamic game analysis. Am. Nat. 173:747-758.

Ratnieks, F. L. W. 1988. Reproductive harmony via mutual policing by workers in eusocial Hymenoptera. Am. Nat. 132:217-236.

Ratnieks, F. L. W., K. R. Foster, and T. Wenseleers. 2006. Conflict resolution in insect societies. Ann. Rev. Entomol. 51:581-608.

Robinson, G. E., C. Strambi, A. Strambi, and M. F. Feldlaufer. 1991. Comparison of juvenile hormone and ecdysteroid haemolymph titres in adult worker and queen honey bees (Apis mellifera). J. Insect Physiol. 37:929935.

Sledge, M. F., F. Boscaro, and S. Turillazzi. 2001. Cuticular hydrocarbons and reproductive status in the social wasp Polistes dominulus. Behav. Ecol. Sociobiol. 49:401-409.

Sledge, M. F., I. Trinca, A. Massolo, F. Boscaro, and S. Turillazzi. 2004. Variation in cuticular hydrocarbon signatures, hormonal correlates and establishment of reproductive dominance in a polistine wasp. J. Insect Physiol. 50:73-83.

Smith, A., B. Hölldobler, and J. Liebig. 2008. Hydrocarbon signals explain the pattern of worker and egg policing in the ant Aphaenogaster cockerelli. J. Chem. Ecol. 34:1275-1282.
Smith, A. A., B. Hölldober, and J. Liebig. 2009. Cuticular hydrocarbons reliably identify cheaters and allow enforcement of altruism in a social insect. Curr. Biol. 19:78-81.

Swanson, W. J., A. G. Clark, H. M. Waldrip-Dail, M. F. Wolfner, and C. F. Aquadro. 2001. Evolutionary EST analysis identifies rapidly evolving male reproductive proteins in Drosophila. Proc. Natl. Acad. Sci. 98:7375-7379.

Thorén, P. A., R. J. Paxton, and A. Estoup. 1995. Unusually high frequency of (CT)n and (GT)n microsatellite loci in a yellowjacket wasp, Vespula rufa (L.) (Hymenoptera: Vespidae). Insect Mol. Biol. 4:141-148.

van Zweden, J. S. 2010. The evolution of honest queen pheromones in insect societies. Commun. Integr. Biol. 3:50-52.

van Zweden, J. S., J. Heinze, J. J. Boomsma, and P. d'Ettorre. 2009. Ant queen egg-marking signals: matching deceptive laboratory simplicity with natural complexity. PLoS ONE 4(3):e4718.

Weil, T., K. Hoffmann, J. Kroiss, E. Strohm, and J. Korb. 2009. Scent of a queen - cuticular hydrocarbons specific for female reproductives in lower termites. Naturwissenschaften 96:315-319.

Wenseleers, T., H. Helanterä, A. G. Hart, and F. L. W. Ratnieks. 2004. Worker reproduction and policing in insect societies: an ESS analysis. J. Evol. Biol. 17:1035-1047.

Wenseleers, T., and F. L. W. Ratnieks. 2006a. Comparative analysis of worker policing and reproduction in eusocial Hymenoptera supports relatedness theory. Am. Nat. 168:E163-E179.

2006b. Enforced altruism in insect societies. Nature 444:50.

Wenseleers, T., A. Tofilski, and F. L. W. Ratnieks. 2005. Queen and worker policing in the tree wasp Dolichovespula sylvestris. Behav. Ecol. Sociobiol. 58:80-86.

Wilson, E. O. 1971. The insect societies. Harvard Univ. Press, Cambridge, MA.

Yamazaki, Y., M. Kiuchi, H. Takeuchi, and T. Kubo. 2011. Ecdysteroid biosynthesis in workers of the European honeybee Apis mellifera $\mathrm{L}$. Insect Biochem. Mol. Biol. 41:283-293.

Zahavi, A. 1975. Mate selection-a selection for a handicap. J. Theor. Biol. 53: 205-214.

Associate Editor: M. Reuter

\section{Supporting Information}

Additional Supporting Information may be found in the online version of this article at the publisher's website:

Figure S1. Typical CHC profile of a sterile worker (SW) of Dolichovespula saxonica.

Figure S2. Predicted and observed proportions of egg-laying workers. Line depicts predicted $=$ observed.

Table S1. Principal Components of CHC Variation, Their Diagnostic Properties, and Their Relationships with the Variables Reproductive Caste and Colony.

Table S2. A Numeric Version of Figure 3, Also Including the Average Percentage of Each CHC Found on the Cuticles of Queens (Q), Reproductive (RW) and Sterile workers (SW).

Table S3. Data on the Percentage of Reproductive Workers in Colonies of Dolichovespula saxonica and Vespula vulgaris.

Table S4. Notation and Definition of Parameters Used in Supporting Information Methods.

Table S5. Data on Effectiveness of Policing, Relatedness Among Workers, Colony Size, Queen-Worker Dimorphism, Relative Queen Fecundity, and Observed (obs) and Predicted (pred) Percentage of Egg-laying Workers in Eight Species of Vespine Wasps.

Methods. Estimated proportion of reproductive workers. 